BNL- 65452

Informal Report

\title{
Fossil Fuel Decarbonization Technology for Mitigating Global Warming
}

by

\author{
Meyer Steinberg \\ Brookhaven National Laboratory \\ Upton, New York 11973
}

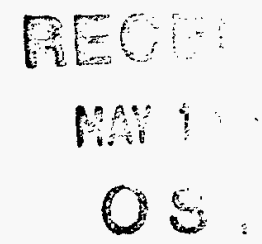

1997- 1998

\author{
Engineering Technology Division \\ Department of Advanced Technology, Brookhaven National Laboratory \\ Upton, New York 11973 \\ Prepared for the U.S. Departrment of Energy \\ Washington, DC \\ Contract No. DE-AC02-98CH10886
}


Disclaimer

This report was prepared as an account of work sponsored by an agency of the United States Government. Neither the United States Government nor any agency thereof, nor any of their employees, or any of their contractors, subcontractors, or their employees, makes any warrantee, expressed or implied, or assumes any legal liabilities or responsibility for the accuracy, completeness, or usefulness of an information, apparatus, product, or process disclosed, or represents that its use would not infringe privately owned rights. Reference herein to any specific commercial product, process or service by trade name, trademark, manufacturer, or otherwise, does not necessarily constitute or imply its endorsement, recommendation, or favoring by the United States Government or any agency, contractor, or subcontractor thereof. The views and opinions of authors expressed herein do not necessarily state or reflect those of the United States Government or any agency contractor or subcontractor thereof. 


\title{
Fossil Fuel Decarbonization Technology for Mitigating Global Warming
}

\author{
By \\ Meyer Steinberg \\ Brookhaven National Laboratory \\ Engineering Technology Division \\ Department of Advanced Technology \\ Upton, NY 11973
}

Tel: (516) 344-3036

Fax: (156) 344-4255

DistRIBUTION OF THIS DOCUMENT Is UNLIMITED fh MASTER

$1997-1998$

This work was performed under the auspices of the Department of Energy 


\title{
NATURAL GAS DECARBONIZATION TECHNOLOGY FOR MITIGATING GLOBAL WARMING
}

\author{
Meyer Steinberg \\ Brookhaven National Laboratory \\ Upton NY 11747 \\ $1997-1998$
}

\section{$\underline{\text { Abstract }}$}

It has been understood that production of hydrogen from fossil and carbonaceous fuels with reduced $\mathrm{CO}_{2}$ emission to the atmosphere is key to the production of hydrogen-rich fuels for mitigating the $\mathrm{CO}_{2}$ greenhouse gas climate change problem. The conventional methods of hydrogen production from fossil fuels (coal, oil, gas and biomass) include steam reforming and water gas shift mainly of natural gas (SRM). In order to suppress $\mathrm{CO}_{2}$ emission from the steam reforming process, $\mathrm{CO}_{2}$ must be concentrated and sequestered either in or under the ocean or underground (in aquifers, or depleted oil or gas wells). Up to about $40 \%$ of the energy is lost in this process. An alternative process is the pyrolysis or the thermal decomposition of methane, natural gas (TDM) to hydrogen and carbon. The carbon can either be sequestered or sold on the market as a materials commodity or used as a fuel at a later date under less severe $\mathrm{CO}_{2}$ restraints. The energy sequestered in the carbon amounts to about $42 \%$ of the energy in the natural gas resource which is stored and not destroyed. A comparison is made between the well developed conventional SRM and the less developed TDM process including technological status, efficiency, carbon management and cost. The TDM process appears to have advantages over the well developed SRM process. It is much easier to sequester carbon as a stable solid than $\mathrm{CO}_{2}$ as a reactive gas or low temperature liquid. It is also possible to reduce cost by marketing the carbon as a filler or construction material. The potential benefits of the TDM process justifies its further efficient development. The hydrogen can be used as a transportation fuel or converted to methanol by reaction with $\mathrm{CO}_{2}$ from fossil fuel fired power plant stack gases, thus allowing reuse of the carbon in conventional IC automobile engines or in advanced fuel cell vehicles. 


\title{
FOSSIL FUEL DECARBONIZATION TECHNOLOGY FOR MITIGATING GLOBAL WARMING
}

\author{
by \\ Meyer Steinberg \\ Brookhaven National Laboratory \\ Upton NY 11747 \\ 1997-1998
}

\section{$\underline{\text { Introduction }}$}

The International Panel (of the UN) on Climate Change (IPCC) representing the consensus of thousands of leading world scientists has concluded that there is discerning evidence that global warming has already taken place and that this will increase significantly within the next century ${ }^{(1)}$. This panel has alerted the world community to begin considering mitigating the global warming effect by curtailing the increase in concentration of the major greenhouse gas $\mathrm{CO}_{2}$ in the atmosphere mainly due to its emission from combustion of fossil fuels. The Kaya equation ${ }^{(2)}$ teaches that a country's net $\mathrm{CO}_{2}$ emission to the atmosphere is a function of (1) population, (2) the per capita domestic product generated, (3) the energy generated per gross domestic product, and (4) the carbon emission per unit energy. This equation has been modified by including a negative term which includes the removal of $\mathrm{CO}_{2}$ from the atmosphere and disposal in some sink. Based on this general equation, the following mitigating paths are possible to limit the $\mathrm{CO}_{2}$ emission.

1. Limit population growth.

2. Improve the efficiency of conversion and utilization of energy.

3. Utilize non-fossil energy sources - nuclear, solar, wind, hydro, and geothermal energy.

4. Increase biomass production and utilization including forestation, agriculture and aquaculture (algae, etc).

5. Decarbonization of fossil fuels.

6. Sequestration of carbon from fossil fuels.

Because of the near term problems with the utilization of non-fossil energy sources, which include availability, cost and safety factors, it appears its development will be slow. However, current use of fossil fuels as an energy source upon which most of the world presently relies, continues to increase its worldwide utilization especially in developing countries. This is due to fossil energy's large resource base, its general availability at reasonable cost, and the large investment in technology and infrastructure which utilizes fossil energy. Thus, it is necessary to seek $\mathrm{CO}_{2}$ mitigation technologies applied to the use of fossil fuels.

There are basically two methods of preventing $\mathrm{CO}_{2}$ from entering the atmosphere due to the utilization of fossil fuels as an energy source. 
(1) Remove carbon before combustion or (2) remove carbon after combustion. Removal of carbon from fossil fuels prior to combustion requires removal and sequestration of carbon either as $\mathrm{CO}_{2}$ or as elemental carbon. Removal of carbon post combustion requires sequestration of carbon only as $\mathrm{CO}_{2}$. These methods are called decarbonization.

When considering decarbonization prior to combustion of fossil fuels which mainly consist of hydrocarbons, the hydrogen content controls the efficiency of recovery of the remaining energy. Coal with a stoichiometry equivalent to $\mathrm{CH}_{0.8} \mathrm{O}_{0.1-0.2}$, contains the least amount of hydrogen; oil, equivalent to $\mathrm{CH}_{0.8}$, has more hydrogen and natural gas, $\mathrm{CH}_{4}$, has the highest amount of hydrogen. Decarbonization entails a loss of energy contained in the natural resource. Thus for maximizing the residual energy upon decarbonization, natural gas is the most effective resource to use. There are basically two methods for decarbonizing natural gas for the production of hydrogen: (1) steam reforming natural gas (SRM) and sequestering $\mathrm{CO}_{2}$ and (2) thermal decomposition of natural gas (TDM) and sequestering of elemental carbon. A comparison of the pros and cons of these two methods is the main purpose of this paper.

\section{Steam Reforming of Methane (SRM)}

The SRM process consists of reacting methane (from natural gas) with steam to produce $\mathrm{CO}$ and $\mathrm{H}_{2}$ (sometimes called synthesis gas) ${ }^{(3)}$. The $\mathrm{CO}$ is further reacted or shifted with steam (usually called the water gas reaction) to form additional hydrogen and $\mathrm{CO}_{2}$. The $\mathrm{CO}_{2}$ is then removed from the gas mixture to produce a clean stream of hydrogen. Normally the $\mathrm{CO}_{2}$ is vented into the atmosphere. For decarbonization, the $\mathrm{CO}_{2}$ must be sequestered. The process is described below and a schematic flowsheet is shown in Figure 1.

(1) Steam reforming of methane:

$$
\mathrm{CH}_{4}+\mathrm{H}_{2} \mathrm{O}=\mathrm{CO}+3 \mathrm{H}_{2}
$$

This reaction usually takes place over a nickel catalyst in a metal alloy tube at temperatures in the region of $800^{\circ}$ to $1000^{\circ} \mathrm{C}$ and at pressures of 30 to $60 \mathrm{~atm}$. The reaction is equilibrium limited and is highly endothermic requiring heat input of $60 \mathrm{Kcal} / \mathrm{mol} \mathrm{CH}_{4}$ including the heat needed to produce steam from liquid water. The heat for the reaction is provided by heating the outside of the tubular reactor in a furnace fired by a natural gas/air flame. Any impurity, such as sulfur, in the natural gas must be cleaned out usually at the well head prior to SRM.

(2) $\mathrm{CO}$ shift by water gas reaction:

$$
\mathrm{CO}+\mathrm{H}_{2} \mathrm{O}=\mathrm{CO}_{2}+\mathrm{H}_{2}
$$

The hot gases from the steam reformer are cooled producing steam which is used in the process. The steam reacts with the $\mathrm{CO}$ forming additional hydrogen and $\mathrm{CO}_{2}$. The water gas shift reaction also takes place in a tubular reactor at lower temperatures than the steam reformer and at about the same pressure. The reaction energy is about balanced so that little additional heat is required to keep the reaction going. The reaction produces a mixture of $\mathrm{CO}_{2}$ and hydrogen with small amounts of $\mathrm{CO}$. 


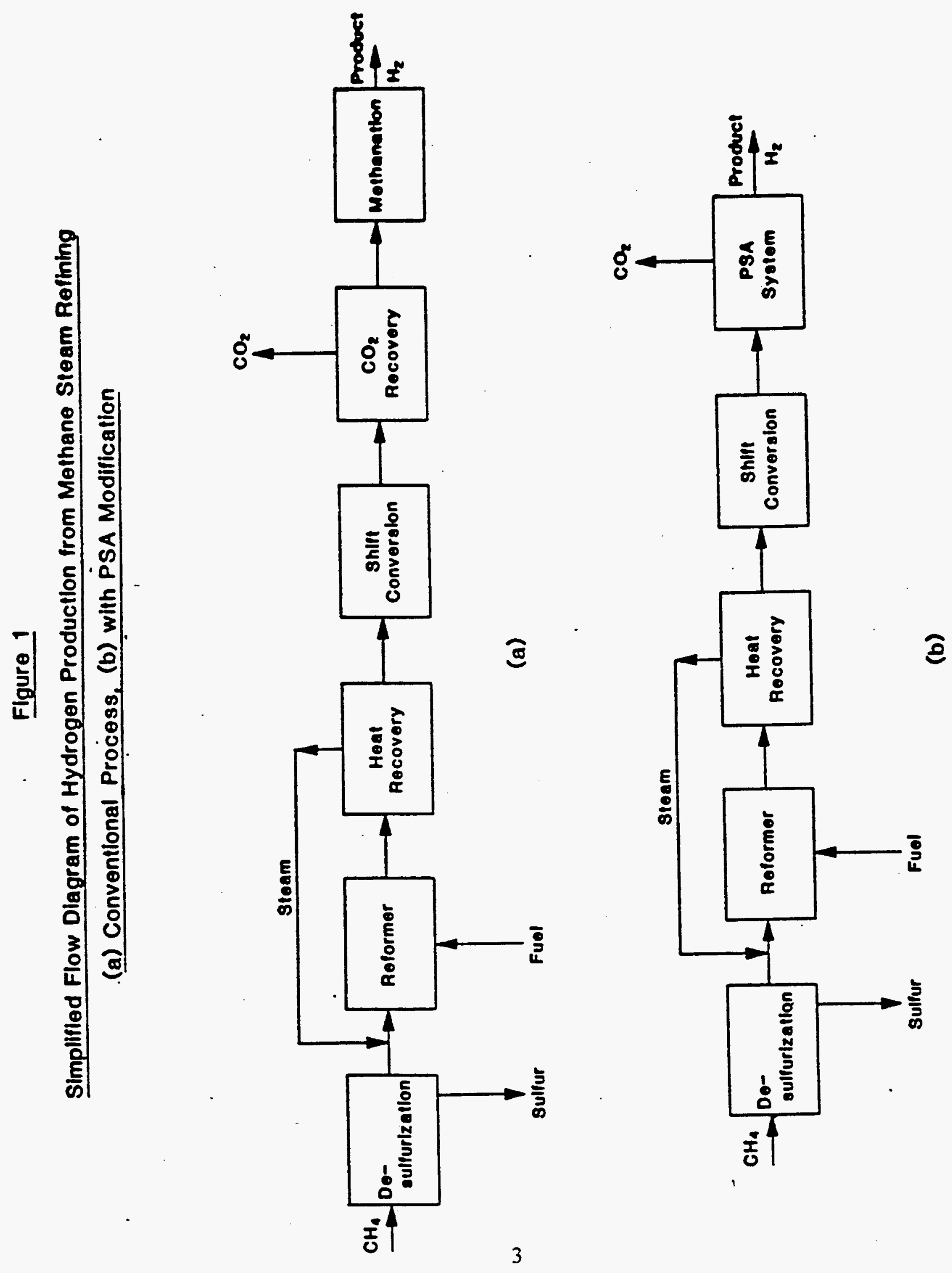


(3) $\mathrm{CO}_{2}$ removal from hydrogen:

The $\mathrm{CO}_{2}$ gas can be separated from the $\mathrm{H}_{2}$ by several methods, including solvent absorption and stripping or by adsorption and stripping over a solid adsorbent to remove and recover the $\mathrm{CO}_{2}$ in a pure stream. The latest, most economical method of $\mathrm{CO}_{2}$ separation is by pressure swing adsorption (PSA). Two reactors are used in tandem. One is pressurized to allow adsorption of the $\mathrm{CO}_{2}$ on a solid adsorbent such as activated carbon, the effluent of which produces a clean stream of hydrogen. The second reactor is depressurized to desorb the $\mathrm{CO}_{2}$ and produce a clean stream of $\mathrm{CO}_{2}$ normally vented to the atmosphere. The flow in the two tandem beds are reversed and the cycle begins again. The overall SRM hydrogen production reaction is then:

$$
\mathrm{CH}_{4}+2 \mathrm{H}_{2} \mathrm{O}=\mathrm{CO}_{2}+4 \mathrm{H}_{2}
$$

Thus 4 mols of $\mathrm{H}_{2}$ are produced per mol of methane, 2 mols coming from methane and 2 coming from the water. The small amount of $\mathrm{CO}$ is sometimes removed in a final reaction step called methanation where the $\mathrm{CO}$ is catalytically reacted with hydrogen to form methane.

$$
\mathrm{CO}+3 \mathrm{H}_{2}=\mathrm{CH}_{4}+\mathrm{H}_{2} \mathrm{O}
$$

The thermal efficiency of the process defined as the energy in the hydrogen produced divided by the energy in the natural gas feedstock including methane needed for firing the furnace is about $75 \%$.

(4) Sequestering $\mathrm{CO}_{2}$ for decarbonization:

When decarbonizing the natural gas for production of hydrogen and preventing the $\mathrm{CO}_{2}$ from entering the atmosphere which causes the global warming, it is necessary to sequester the $\mathrm{CO}_{2}$. Several locations or sinks have been proposed to store or sequester the $\mathrm{CO}_{2}$. (1) in the ocean ${ }^{(4,5)}(2)$ in depleted oil and gas wells ${ }^{(5)}$, (3) in $\mathrm{CO}_{2}$ absorbing minerals ${ }^{(7)}$ and (4) in saline aquifers ${ }^{(8)}$. Each of these locations requires some amount of energy to sequester the $\mathrm{CO}_{2}$.

The SRM process is a well developed process which has been practiced for many years for hydrogen production in petroleum refining for nitrogen fertilizer production and for such bulk chemical production as methanol. $\mathrm{CO}_{2}$ sequestering has never been practiced, although much experimental work has been initiated recently in wells and deep aquifers ${ }^{(5,8)}$.

\section{Thermal Decomposition of Methane (TDM)}

The alternate method for hydrogen production with sequestration of carbon is the thermal decomposition of methan $\mathrm{e}^{(9)}$. When methane is heated to high temperature, the methane decomposes or cracks to carbon and hydrogen:

$$
\mathrm{CH}_{4}=\mathrm{C}+2 \mathrm{H}_{2}
$$

Temperatures above $700^{\circ} \mathrm{C}$ are required and, although lower pressures allow higher feedstock conversions since the reaction is equilibrium limited, higher pressures favor higher rates of reaction ${ }^{(10)}$. The endothermic energy required to perform this reaction is only $18 \mathrm{Kcal} /$ mole to produce $2 \mathrm{mols}$ of 
hydrogen. The carbon produced is usually in particulate form and must be separated from the hydrogen gas stream. The main gaseous product is hydrogen. The energy required to drive this reaction can be supplied in several ways. In the only operating process available currently, called the Carbon Black or Thermal Black Process ${ }^{(11)}$, the heat is provided by heating up a fire brick furnace directly with a methane-air flame to temperatures as high as $1400^{\circ} \mathrm{C}$. The air is then switched off and the methane decomposes on the hot brick until the temperature drops to below $800^{\circ} \mathrm{C}$ when the air is then switched on again to reheat the brick furnace. The system is a semi-continuous process. While one furnace is being heated, the other is decomposing methane and cooling. The furnaces are then reversed for another cycle. This process has been practiced for many years, not for hydrogen production, but for carbon black formation for industrial use in paints, inks, tires, etc. The hydrogen produced is used as fuel to heat the furnace and the methane feedstock.

Other experimental reactors have been used to thermally decompose methane. A fluidized bed thermal decomposition reactor which uses iron oxide for heat transfer and as a catalyst ${ }^{(12)}$. The carbon collected on the iron oxide is burned off in a second riser reactor for reheating the iron oxide and circulated back to the endothermic fluidized bed reactor countercurrent to the methane. Thus, a continuous stream of hydrogen is produced.

Another experimental reactor uses an electric carbon arc which decomposes the methane in a plasma and produces a continuous stream of hydrogen ${ }^{(13)}$. The problem here is that expensive electrical energy is required. When the electrical power is produced from natural gas fuel combustion, even in an efficient combined cycle plant, the overall thermal efficiency is significantly reduced and the $\mathrm{CO}_{2}$ emission per unit energy is significantly increased.

Another proposed MDR reactor consists of a molten metal bath such as molten tin or copper to transfer heat to a methane gas stream in a bubbling bath reactor. The molten metal bath is heated independently through a tubular heat exchanger either by methane-air or hydrogen-air combustion. A schematic of this system is shown in Figure $2^{(14)}$. It is thought that this reactor would be beneficial for heat transfer and carbon separation and removal.

Several methods can be used to separate the carbon from the hydrogen stream. In the Carbon Black process, the particulate carbon flies out of the furnace with the hydrogen gas stream and is separated by bag filters which collects the carbon. A similar system is used in the plasma carbon arc process. However, in the molten metal reactor, it may be possible to capture the carbon in the liquid metal and separate the carbon by density difference, skimming the carbon off from the surface, much as slag is skimmed off the surface of molten iron in a blast furnace.

The separated carbon must then be sequestered, stored or marketed as a materials commodity. Because the carbon is solid, it can be easily handled, transported and stored. The market for carbon black in the U.S. is more than 2 million ton per year which is mainly used as a strengthening agent in tires and in pigments and inks. For mitigating the global warming effect by methane decarbonization by TDM, much larger quantities of carbon will be produced requiring storage. Carbon can be stored in mines and in landfill and at the bottom of the ocean. Uses of carbon as a construction material and in soil conditioning could absorb large quantities of carbon. 
Figure 2

Hydrogen Production by Thermal Decomposition of Natural Gas in a Molten Metal Reactor

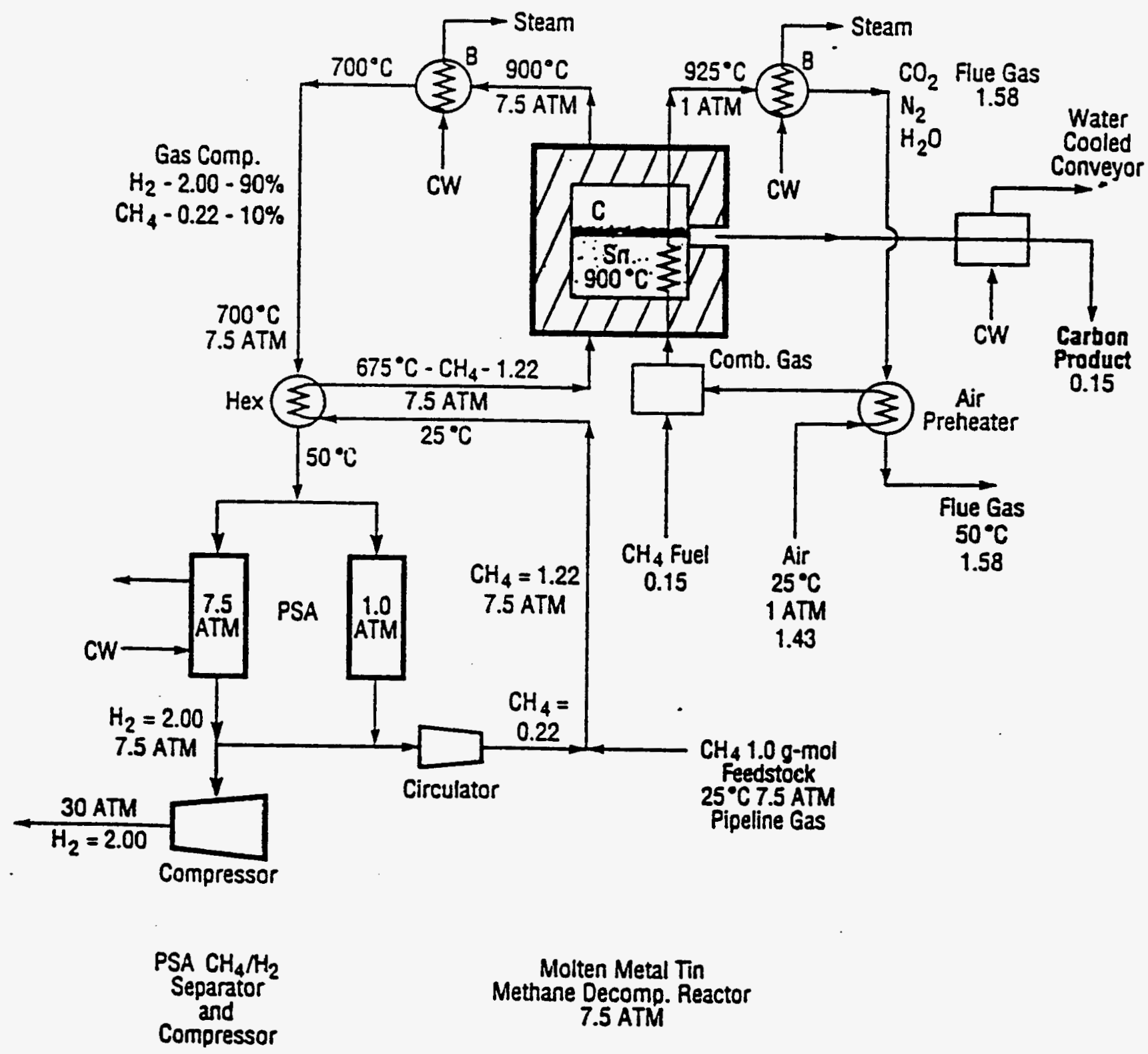


The efficiency of hydrogen production by the thermal carbon black process is estimated to exceed $50 \%{ }^{(11}$. The efficiency of the electric plasma arc process is reported to exceed $90 \%^{(13)}$. A continuous TDM thermal process is in a much lesser state of development for hydrogen production than the highly commercialized SRM process. TDM thus requires much further development effort to bring it into reliable commercial use. On the other hand, the sequestering or storing of solid carbon requires much less development than sequestering gaseous or liquid $\mathrm{CO}_{2}$.

\section{Comparison of SRM with a Potential TDM Process for Decarbonization of Natural Gas}

Table 1 shows a comparison of the parameters of the SRM and TDM processes. Going down the list, SRM produces $4 \mathrm{~mol} \mathrm{H}_{2}$ per mol natural gas while TDM produces only 2. SRM requires 60 $\mathrm{Kcal} / \mathrm{mol}$ for the heat of reaction while TDM requires only 18 . At $80 \%$ thermal efficiency, the heat input to the reactor is $18.8 \mathrm{Kcal} / \mathrm{mol}$ of $\mathrm{H}_{2}$ for SRM and only $11.3 \mathrm{Kcal} / \mathrm{mol}$ of $\mathrm{H}_{2}$ for TDM. The overall process thermal efficiency for SRM is only $75 \%$, because energy is needed to separate the relatively large amounts of $\mathrm{CO}_{2}$ gas from the $\mathrm{H}_{2}$ gas in a pressure swing absorber. For the TDM, the thermal efficiency is down to $58 \%$ because TDM sequesters the carbon and does not use its energy value. Thus SRM emits $155^{\prime} \mathrm{lbs} \mathrm{CO}_{2}$ /MMBTU of hydrogen burned because all the carbon in the methane is converted to $\mathrm{CO}_{2}$. For TDM, only $18 \mathrm{lb} / \mathrm{MMBTU}$ is emitted as $\mathrm{CO}_{2}$ due to the small amount of methane needed to provide the energy for methane decomposition. SRM does not produce any carbon whereas TDM produces $49 \mathrm{lbs}$ of carbon/MMBTU of hydrogen energy.

Comparing the unit operations in the process, SRM needs 3 unit operations whereas TDM needs at most 2 . If the quantity of undecomposed methane is small in TDM, the removal of residual methane may not be necessary, so the process may not need more than one step. For eliminating $\mathrm{CO}_{2}$ emissions, SRM requires sequestering $\mathrm{CO}_{2}$ in the ocean, gas wells, or aquifers. The $\mathrm{CO}_{2}$ must be liquefied and pumped into these locations. A loss of approximately $15 \%$ in energy occurs due to the sequestering operation. In the case of TDM, there is little energy loss since the carbon separates or filters as a solid particulate and solids transport into land fill or mines, or marketing requires very little energy expenditure. The net energy efficiency for $\mathrm{H}_{2}$ production eliminating $\mathrm{CO}_{2}$ emission is $60 \%$ for the SRM process and thus indicates a loss of $40 \%$ in the process of producing $\mathrm{H}_{2}$ avoiding $\mathrm{CO}_{2}$ emission. In the TDM process, the net energy efficiency is $58 \%$ because there is little loss of energy sequestering carbon in the TDM process. The TDM process thus approaches that of the SRM process even though we do not use the energy value of the carbon in the TDM process. Furthermore, the energy in the sequestered carbon from TDM is not lost. It is possible that the stored carbon may be used at a later date when it may become permissible to burn in a less carbon restrictive era in the longer term future. However, in the SRM process $40 \%$ of the energy is lost forever, in the decarbonization and sequestration process. Furthermore, the by-product value of $\mathrm{CO}_{2}$ for SRM is practically nil, since it is difficult to find large scale uses of $\mathrm{CO}_{2}$. On the other hand, the carbon from TDM has a current market value although limited. Potentially more uses can developed for carbon as a materials commodity, and this could significantly reduce the cost of hydrogen from the TDM process. It should also be noted that sequestering $\mathrm{CO}_{2}$ in cavities in the earth or dissolved in the ocean may become environmentally unacceptable. When disposing the $\mathrm{CO}_{2}$ in the ocean, the $\mathrm{pH}$ at the point of injection could cause a decrease in the surrounding $\mathrm{pH}$ which could have a significant harmful effect on marine life. Pressurizing $\mathrm{CO}_{2}$ in wells could conceivably cause underground 
Table 1

\section{Comparison Between Reforming and Pyrolysis of Natural Gas for Hydrogen Production}

\begin{tabular}{|c|c|c|}
\hline ITEM & SRM - REFORMING & TDM - PYROLYSIS \\
\hline Reaction Chemistry & $\mathrm{CH}_{4}+2 \mathrm{H}_{2} \mathrm{O}=\mathrm{CO}_{2}+4 \mathrm{H}_{2}$ & $\mathrm{CH}_{4}=\mathrm{C}+2 \mathrm{H}_{2}$ \\
\hline Mols $\mathrm{H}_{2} \mathrm{pr} \mathrm{mol} \mathrm{CH}_{4}$ & 4 & 2 \\
\hline $\begin{array}{c}\text { Endothermic Ht of Reaction } \\
\mathrm{Kcal} / \mathrm{mol} \mathrm{CH}_{4}\end{array}$ & 60 & 18 \\
\hline $\begin{array}{l}\text { At } 80 \% \text { Thermal Eff. Process } \\
\text { Heat in } \mathrm{Kcal} / \mathrm{mol} \mathrm{H}_{2}\end{array}$ & 18.8 & 11.3 \\
\hline $\begin{array}{l}\text { Process Thermal Efficiency for } \\
\mathrm{H}_{2} \text { Production - } \%\end{array}$ & 75 & 58 \\
\hline $\begin{array}{l}\mathrm{CO}_{2} \text { Emission } \\
\quad \mathrm{Mols} \mathrm{CO}_{2} / \mathrm{mol} \mathrm{H}_{2} \\
\end{array}$ & 0.43 & 0.05 \\
\hline Lbs $\mathrm{CO}_{2} \mathrm{Gas} / \mathrm{MMBTU}$ & 155 & 18 \\
\hline Lbs C Solid MMBTU & 0 & 49 \\
\hline Process Unit Operations & $\begin{array}{l}\text { 1. Reformer } \\
\text { 2. Shift } \\
\text { 3. } \mathrm{CO}_{2} \text { separation } \\
\end{array}$ & $\begin{array}{l}\text { 1. Pyrolyzer } \\
\text { 2. } \mathrm{CH}_{4} \text { Separation if needed }\end{array}$ \\
\hline $\begin{array}{l}\text { Sequestration } \\
\% \text { Net Energy Reduction }\end{array}$ & $\begin{array}{l}\text { Liq. } \mathrm{CO}_{2} \text {, in ocean, gas wells, } \\
\text { aquifers }=\sim 15 \%\end{array}$ & $\begin{array}{l}\text { Solid } \mathrm{C} \text {, in land fill, mines or } \\
\text { market }=\sim 0 \%\end{array}$ \\
\hline Net Energy Efficiency \% & $\begin{array}{l}75-15=60 \% \\
\text { Energy Lost }=40 \%\end{array}$ & $\begin{array}{c}58 \% \\
\text { Energy Stored }=42 \%\end{array}$ \\
\hline By-Product Value & Low & High materials potential \\
\hline Uncertainties & $\begin{array}{l}\text { Possible Hazardous } \\
\text { Environmental Effects }\end{array}$ & Minimal \\
\hline Process Development & Well developed & Needs development \\
\hline
\end{tabular}


structural damage and allow even catastrophic release of $\mathrm{CO}_{2}$ which could cause asphyxiation to air breathing animals and humans. Because of its physical benign form, the uncertainties in sequestration of elemental solid carbon should be minimal.

A preliminary cost estimate of $\mathrm{TDM}^{(3)}$ shows that the cost of producing hydrogen by TDM is approximately the same as that for SRM before sequestration of either $\mathrm{CO}_{2}$ or C. Since the cost of sequestering $\mathrm{CO}_{2}$ is greater than that of $\mathrm{C}$, the TDM process should be less expensive than SRM.

The hydrogen can be used as a transportation fuel or converted to methanol by reaction with $\mathrm{CO}_{2}$ from fossil fuel-fired power plant stack gases, thus allowing reuse of the carbon in conventional IC automobile engines or in advanced fuel cell vehicles.

The bottom line is that TDM has great potential in producing fuel without $\mathrm{CO}_{2}$ emission; however, it requires development of a thermally efficient process. The potential benefits of TDM versus the SRM certainly justifies spending the effort in developing the production of hydrogen by the TDM routes for mitigating the global warming effect.

\section{REFERENCES:}

1. International Panel on Climate Change, "Climate Change 1995" Houghton, et al (Ed.), Cambridge University Press, Cambridge, UK (1996).

2. Kaya, Y., et al. "A Grand Strategy for Global Warming". Paper presented at Tokyo Conference on Global Environment, (September 1989).

3. Steinberg, M. and Cheng, H.C. "Modern and Prospective Technologies for Hydrogen Production from Fossil Fuels", J. Hydrogen Energy 14 No. 1 797-820 (1989).

4. Steinberg, M., Cheng, H.C., and Horn, F. "A System Study for Removal, Recovery and Disposal of $\mathrm{CO}_{2}$ from Fossil Fuel Power Plants in the U.S.," BNL 35666, Brookhaven National Laboratory, Upton, NY (May 1984).

5. Herzog, H., Drake E., and Adams, E. " $\mathrm{CO}_{2}$ Capture, Reuse and Storage Technologies for Mitigating Global Climate Change - A White Paper," Final Report. Massachusetts Institute of Technology, Cambridge, MA (January 1997).

6. Horn, F.L. and Steinberg, M. "Carbon Dioxide Power Plant for Total Emissions Control and Enhanced Oil Recovery." BNL 30046, Brookhaven National Laboratory, Upton, NY (August 1981) and BNL 51597 ( (September 1982).

7. Lackner, K.S., Batt, E.P. "Carbon Dioxide Disposal in Mineral Carbonate," Proceedings of the 3rd International Conference on Carbon Dioxide Removal ICCDR-3, Cambridge, MA (1996). 
8. Bergman, P.D., Winter, E.M. "Disposal of $\mathrm{CO}_{2}$ in Deep Saline Aquifers in the U.S.," U.S./Japan Joint Technical Workshops, U.S. Department of Energy, State College, PA (September 30-October 2, 1996).

9. Steinberg, M. "The Hy-C Process (Thermal Decomposition of Natural Gas) Potentially the Lowest Cost Source of Hydrogen with the Least $\mathrm{CO}_{2}$ Emission." BNL 61364, Brookhaven National Laboratory, Upton, NY (December 1994).

10. Steinberg, M. "Production of Hydrogen and Methanol from Natural Gas with Reduced $\mathrm{CO}_{2}$ Emission," Proceedings of the 11th World Hydrogen Energy Conference (WHEC), Stuttgart, Germany, Vol. 1 499-510 (June 23-28, 1996).

11. Donnet, J.B. Carbon Black, pp 16-18, Marcel Dekker, New York (1976).

12. Pohleny J.B. and Scott, N.H. "Method of Hydrogen Production by Catalytic Decomposition of a Gaseous Hydrogen Stream," U.S. Patent 3, 284, 161 assigned to Universal Oil Products Co (November 8, 1966) and Chemical Engineering 69, 90-1 (1962).

13. Gaudermack, B. And Lynum, S. "Hydrogen Production from Natural Gas Without Release of $\mathrm{CO}_{2}$ to the Atmosphere." Proceedings of the 11th World Hydrogen Energy Conference, 511-523, Coco Beach, Florida (June 1996)

14. Steinberg, $\mathrm{M}$. "The Carnol Process for $\mathrm{CO}_{2}$ Mitigation from Power Plants and the Transportation Sector." BNL 62835, Brookhaven National Laboratory, Upton, NY (December 1995). 
M98004978

Report Number (14)

BNL -65452

Publ. Date (11) 1998

Sponsor Code (18) DOE/EH

uC Category (19) UC-600, DOE/ER

19980622025

DIIC QUATHTY IMOPECTED 1

DOE 